\title{
Thermophysical Properties of Aluminum 1060 Fabricated by Equal Channel Angular Pressing
}

\author{
Sanghyun Lee • Suyong Kwon • Jong-Cheon Lee • \\ Seoung-Won Lee
}

Received: 8 August 2011 / Accepted: 21 February 2012 / Published online: 8 March 2012

(C) The Author(s) 2012. This article is published with open access at Springerlink.com

\begin{abstract}
Equal channel angular pressing (ECAP) has the advantage of enabling an ultrafine grain size. Aluminum 1060 is used as a power plant material because of its favorable electrical properties. However, the weak strength of aluminum limits its application. In this study, the thermal conductivity and electrical conductivity of $\mathrm{Al}$ 1060 made by ECAP was investigated. ECAP was conducted through the die having a channel angle of $90^{\circ}$ and a corner angle of $20^{\circ}$ at a temperature of $473 \mathrm{~K}$ with a strain rate of $2 \mathrm{~mm} \cdot \mathrm{s}^{-1}$. The specimen was then processed with 1 to 8 passes by the route $\mathrm{Bc}$ method with $90^{\circ}$ rotation. In the case of eight passes, the grain size was reduced to as small as $300 \mathrm{~nm}$. As a result of the ECAP, the tensile strength was raised from $75 \mathrm{MPa}$ to $134 \mathrm{MPa}$, while the electrical conductivity did not show a significant difference after eight passes. The thermal conductivity gradually decreased with ECAP passes, because of the decreased grain size by ECAP.
\end{abstract}

Keywords Aluminum $1060 \cdot$ Equal channel angular pressing (ECAP) · Grain size · Thermal conductivity

\footnotetext{
S. Lee · S. Kwon $(\varangle)$

Division of Physical Metrology, Korea Research Institute of Standards and Science, 267 Gajeong-ro, Yuseong-gu, Daejeon, 305-340, Republic of Korea

e-mail: kweonsy@kriss.re.kr

J.-C. Lee

R\&D team, Khancera Co., Daejeon, 306-230, Republic of Korea

S.-W. Lee

Department of Nanomaterial Engineering, Chungnam National University,

Daejeon, 305-764, Republic of Korea
} 


\section{Introduction}

Equal channel angular processing (ECAP) is a method of severe plastic deformation that enables a high level of strain without changes in surface area and is being used to refine grain size to a submicron or smaller level [1]. For metal materials, the strength increases with decreasing grain sizes. Use of ECAP has been studied for the grain refinement of metals, including steel, aluminum, and copper [2-6]. In particular, the grain refinement of aluminum alloys below submicron size has been difficult due to the low-temperature recovery with a high stacking fault energy, but ECAP application enables a significant improvement [1]. Characteristics of superplasticity due to high grain boundary formation are reported at low temperature as well [7,8]. Aluminum 1060 contains $99.6 \%$ aluminum and slight amounts of silicon and iron as impurities. It is also a common conductor among 1xxx alloys used as materials for power transmission or distribution systems. Despite its superior electrical properties, aluminum 1060 has low strength and thus requires heat treatment and rolling.

This study used ECAP on aluminum 1060 to refine its structure, and then observed the strength with increasing passes; the mechanical properties of the refined structure; and the changes in thermophysical properties of ultrafine grained aluminum. ECAP was used to improve strength through refinement, and thus to enhance mechanical properties, while maintaining electrical properties. The thermal conductivity was calculated from the measured values of the specific heat capacity, thermal diffusivity, and density. Four-probe electrical-resistivity measurements were taken, and the electrical conductivity was calculated with the thermal conductivity using the Wiedemann-Franz method.

\section{Experimental}

An aluminum 1060 alloy with $99.6 \%$ purity was used for this study. The extrudate is processed into a round bar specimen with a diameter of $17.5 \mathrm{~mm}$ and a length of $125 \mathrm{~mm}$, and was treated with annealing at $723 \mathrm{~K}$ for $2 \mathrm{~h}$. The specimen was processed through the die having a channel angle $(\Phi)$ of $90^{\circ}$ and a corner angle $(\Psi)$ of $20^{\circ}$ at a temperature of $473 \mathrm{~K}$ with a strain rate of $2 \mathrm{~mm} \cdot \mathrm{s}^{-1}$, with 1 to 8 passes via route $\mathrm{Bc}$ with a strain rate of $2 \mathrm{~mm} \cdot \mathrm{s}^{-1}$ [9]. $\mathrm{MoS}_{2}$ lubricant was applied on the surface of the specimen to minimize friction between the die and specimen during ECAP.

Densities were measured using the Archimedes method at room temperature, but for the high-temperature region, they were calculated from the measurement of the coefficient of thermal expansion. A differential scanning calorimeter (DSC: Netzsch, DSC 404C) was used for the measurement of the specific heat capacity, with calibration using indium, tin, zinc, aluminum, and gold (99.9999\%). The DSC environment was conditioned by the flow of inert gas (argon, $99.999 \%$ ) at $50 \mathrm{~mL} \cdot \mathrm{min}^{-1}$. Specific heat capacities were measured while the temperature was raised between room temperature to $600^{\circ} \mathrm{C}$ at a rate of $10 \mathrm{~K} \cdot \mathrm{min}^{-1}$, and the averaged specific heat capacity of each $50^{\circ} \mathrm{C}$ temperature interval was taken. Each specimen was processed to have 
a diameter of $4 \mathrm{~mm}$ and thickness of about $2 \mathrm{~mm}$, and the NIST SRM-720 ( $\alpha$-sapphire) standard material was used. The thermal expansion coefficient was measured using methods from a dilatometer (Netzsch, DIL 402C) raising the temperature at $5 \mathrm{~K} \cdot \mathrm{min}^{-1}$ in an environment of pure nitrogen $(99.999 \%)$ at $50 \mathrm{~mL} \cdot \mathrm{min}^{-1}$. The thermal diffusivity was measured by the laser flash method (ULVAC, TC-7000) [10] with a correction by the Azumi method [11]. The TEM specimen was polished with $90 \mu \mathrm{m}$ sand paper, and then jet polishing was conducted with $25 \%$ nitric acid and $75 \%$ methanol under $25 \mathrm{~V}$ voltage at $-30^{\circ} \mathrm{C}$. JEOL Model 2010 was used as the transmission electron microscope (TEM), conditioned with an acceleration voltage of $200 \mathrm{keV}$.

\section{Results and Discussion}

\subsection{Microstructure and Grain Size Distribution}

Figure 1 from the optical microscope shows the microstructure of Al 1060 as received. The grain size is about (200 to 300) $\mu \mathrm{m}$ on average. Parallel subgrain bands formed on the entire surface of the 1 pass case, as shown in Fig. 2a. The grain size is about (600 to 700$) \mathrm{nm}$. The several dislocations on the grain boundary are observed to be irregularly placed. The subgrain band in the 2 passes case, in Fig. 2b, was especially wide, whereas the grain size was $\sim 500 \mathrm{~nm}$. Grain sizes in 4 passes and 8 passes, shown in Figs. $2 \mathrm{c}$ and d, decreased to $400 \mathrm{~nm}$ and $300 \mathrm{~nm}$, respectively, and the grain appears to be more homogenously formed compared to the one after 2 passes. We found that the grains are more finely and homogenously formed with the increase of ECAP, except that 1 pass and 2 passes had inhomogeneous structures.

Figure 3 shows the grain size distribution by number of passes in ECAP, for the association analysis between the thermal diffusivity and grain size. The size of grains gradually decreases as the number of ECAP passes increases. Specifically, we

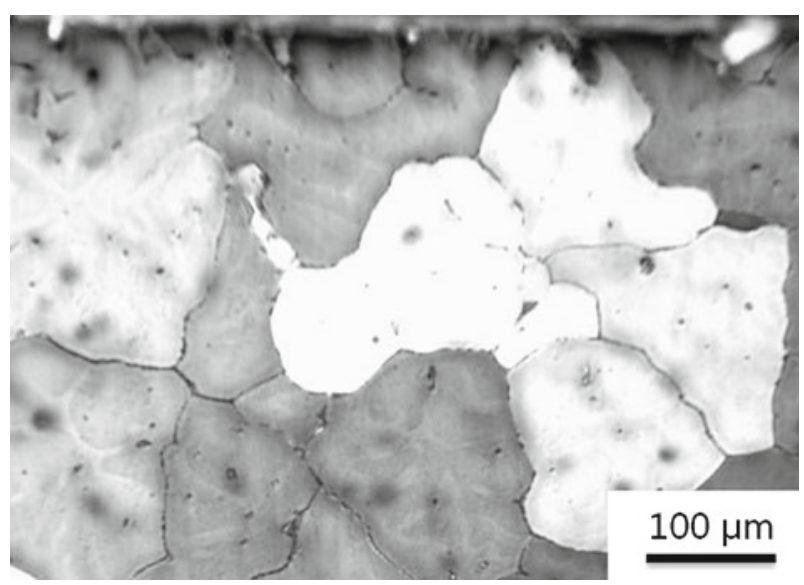

Fig. 1 Micrographs of aluminum 1060 as-received from the optical microscope 

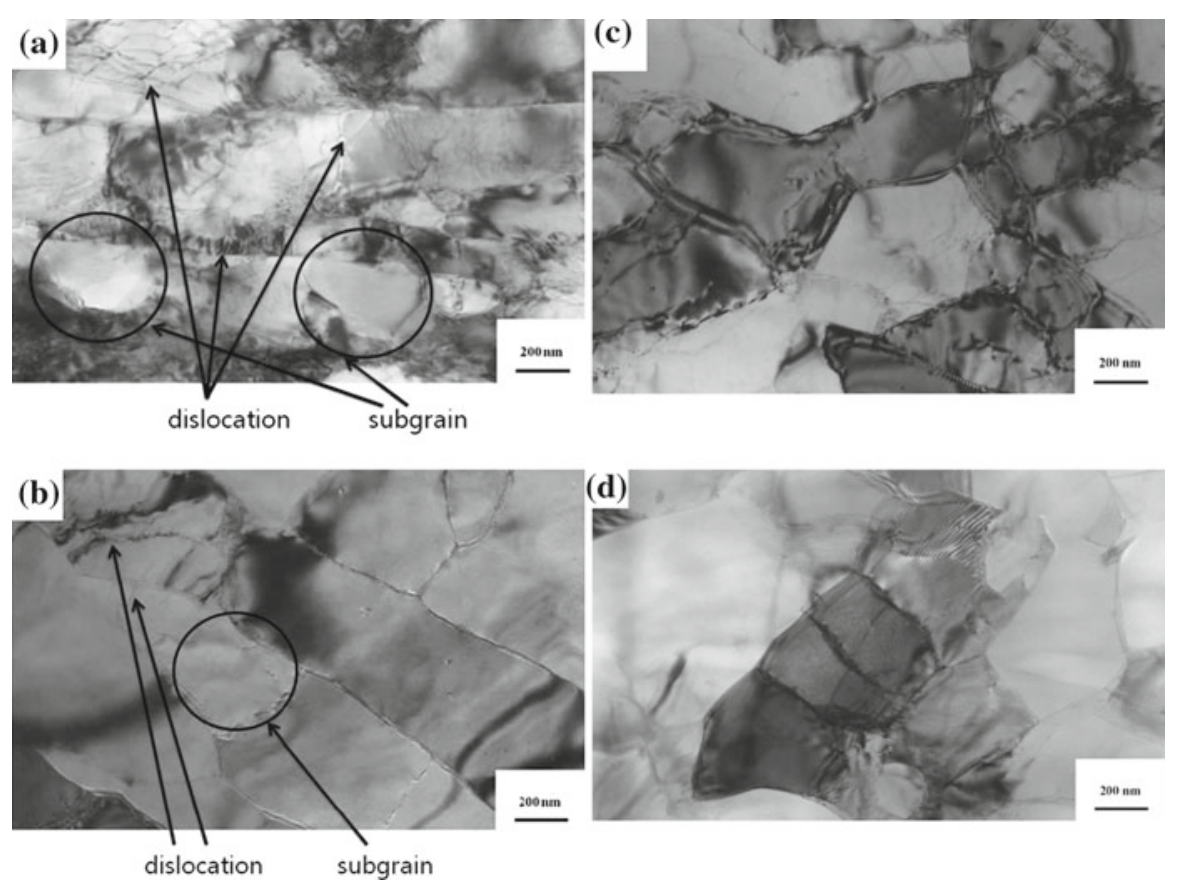

Fig. 2 TEM micrographs of aluminum 1060, Route Bc; (a) 1 pass, (b) 2 passes, (c) 4 passes, and (d) 8 passes

observe that the original grain size, (200 to 300) $\mu \mathrm{m}$, becomes refined to be $600 \mathrm{~nm}$ (after 1 pass), $500 \mathrm{~nm}$ (after 2 passes), $400 \mathrm{~nm}$ (after 4 passes), and $300 \mathrm{~nm}$ (after 8 passes). Gendelmana [6] claimed that the small distribution of grain size increases the reflectance of electrons, which eventually decreases the thermal conductivity in ECAP-deformed ultrafine grained coppers. The result of this study with ECAPdeformed ultrafine grained aluminum 1060 agrees with this. In the case of ECAPdeformed ultra-fine-grained coppers, it was further reported that the decrease of thermal conductivity by ECAP passes is related to and conditional on the grain distribution for the particular pass [6]. Grain refinement by severe plastic deformation is generated by the formation of dislocations, whereafter various dislocations produced after ECAP interfere with the conduction of electrons. Such an interruption of thermal flow eventually reduces the thermal and electrical conductivities. As dislocations form a network of subgrains that refines the grain structure, the analysis of the grain size distribution is particularly significant in interpreting changes of thermal conductivity. In summary, the refinement of grains by severe plastic deformation forms a subgrain from the network of ECAP-induced dislocations. The dislocations disturb the flow of electrons, and act as the most definitive factor lowering electrical and thermal conductivities. Therefore, the analysis of the equilibrium grain size distribution function is extremely important in understanding changes in thermal conductivity. 

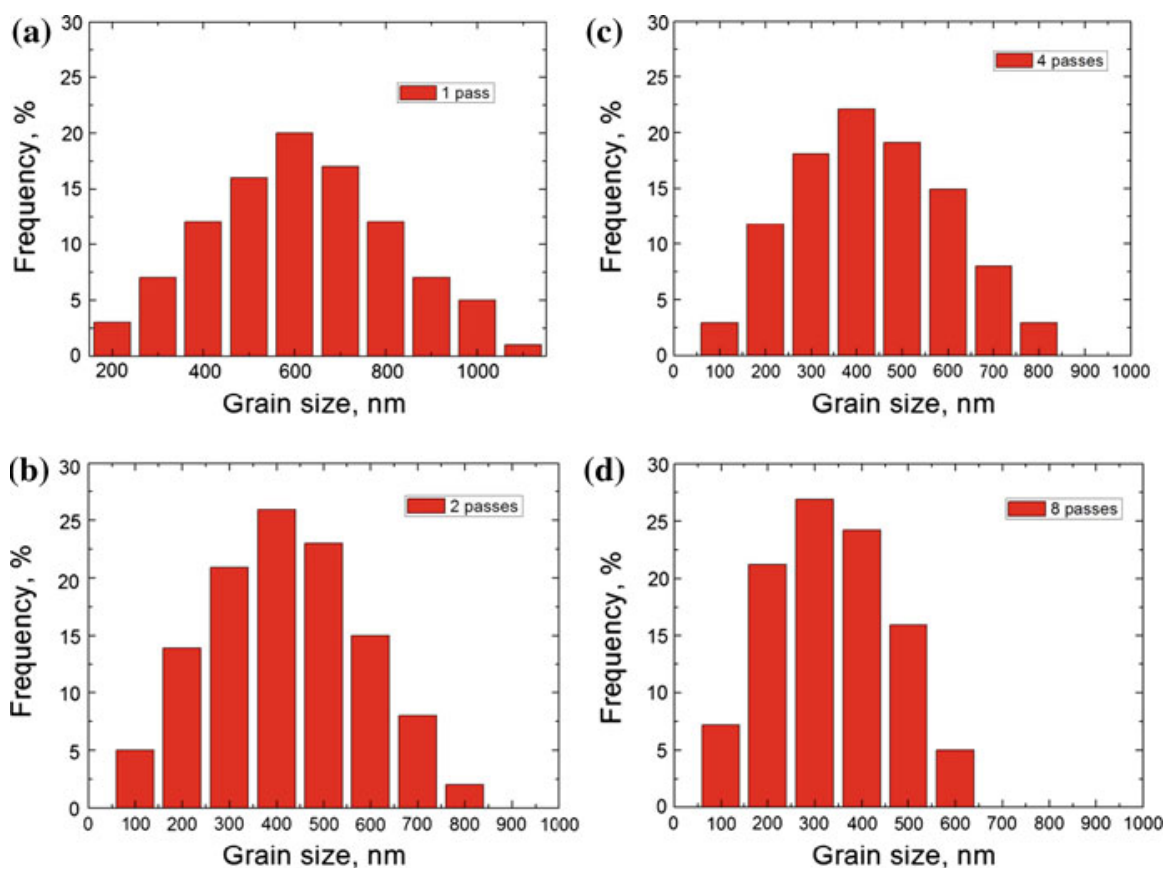

Fig. 3 Grain size distribution with the number of ECAP passes measured by TEM: (a) 1 pass, (b) 2 passes, (c) 4 passes, and (d) 8 passes

\subsection{Tensile Testing at Room Temperature}

Figure 4 shows the level of engineering stress versus engineering strain, at the asreceived and post-ECAP stages. In the as-received state, the specimen has a yield strength, tensile strength, and elongation of $62 \mathrm{MPa}, 75 \mathrm{MPa}$, and $38 \%$, respectively. After 1 pass, the yield strength became $121 \mathrm{MPa}$ and the tensile strength was $134 \mathrm{MPa}$, an increase of twice the original level, and the elongation decreased to $15 \%$. The results from 2 passes were not particularly different from those from 1 pass, whereas the tensile strength slightly decreased to $129 \mathrm{MPa}$ after 4 passes, and increased back to $\sim 142 \mathrm{MPa}$ after 8 passes. After the increase in the ECAP pass, the strength was not further improved with an increasing number of ECAP passes, and no further change in elongation was observed after the decrease from $38 \%$ to $15 \%$ at the 1 pass stage. It can thus be concluded that the improvement in strength can be anticipated with even one ECAP pass.

\subsection{Thermophysical Properties}

Figure 5 shows the result of specific heat capacity measurements between room temperature and $600{ }^{\circ} \mathrm{C}$ using the enthalpy method. The specific heat capacity of the as-received material is $0.9349 \mathrm{~J} \cdot \mathrm{g}^{-1} \cdot \mathrm{K}^{-1}$ at room temperature. This decreases to $0.9265 \mathrm{~J} \cdot \mathrm{g}^{-1} \cdot \mathrm{K}^{-1}$ after 1 pass, $0.9232 \mathrm{~J} \cdot \mathrm{g}^{-1} \cdot \mathrm{K}^{-1}$ after 2 passes, $0.9279 \mathrm{~J} \cdot \mathrm{g}^{-1} \cdot \mathrm{K}^{-1}$ 


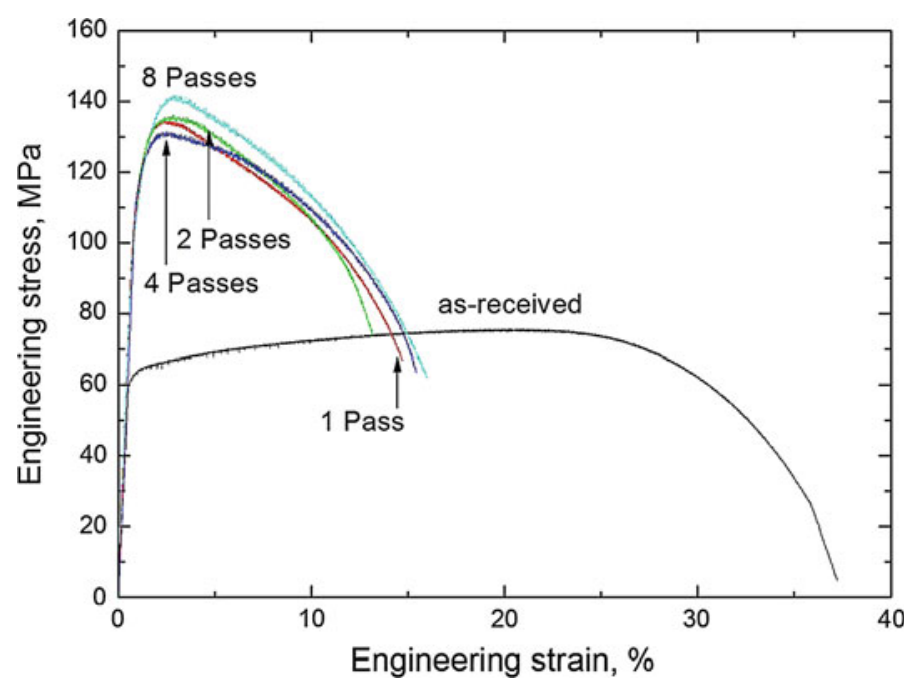

Fig. 4 Engineering stress-strain curves for ECAP aluminum 1060

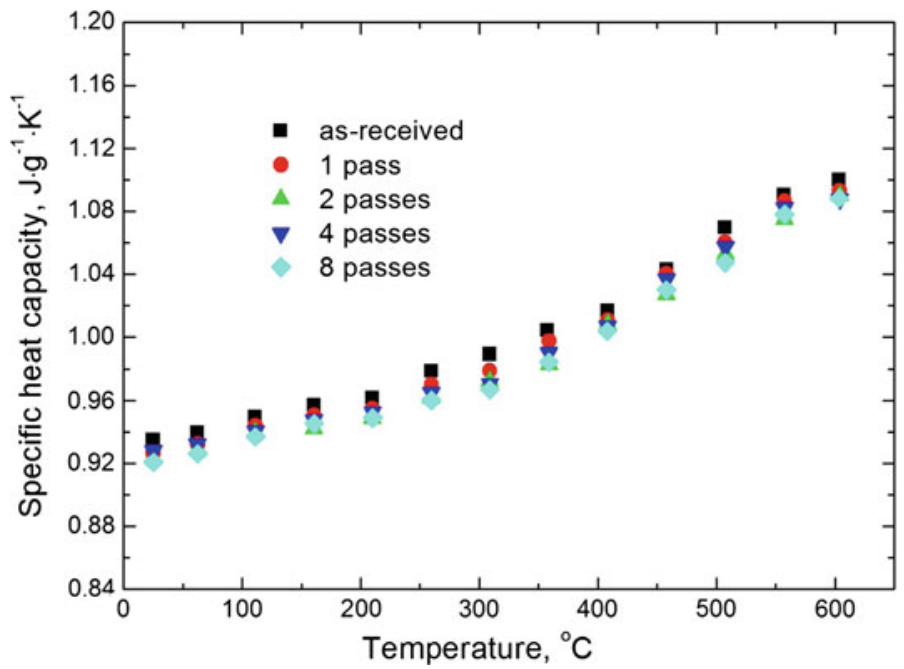

Fig. 5 Specific heat capacity of ECAP aluminum 1060

after 4 passes, and then to $0.9209 \mathrm{~J} \cdot \mathrm{g}^{-1} \cdot \mathrm{K}^{-1}$ after 8 passes, which is a $1.5 \%$ decrease from the as-received state at room temperature. The difference remained constant up to $600{ }^{\circ} \mathrm{C}$. Although it is within the range of $\pm 2 \%$, the combined uncertainty, the difference remained constant in repeated experimental results. The decrease of the specific heat capacity is considered to be the effect of grain size and deformation by ECAP. But this difference by ECAP is $<2 \%$, and within the uncertainty of the system.

Figure 6 shows the thermal diffusivity of aluminum 1060 at different stages-in the as-received state and by the number of ECAP passes-measured by the half-time method. At room temperature, the thermal diffusivity was $9.26 \times 10^{-5} \mathrm{~m}^{2} \cdot \mathrm{s}^{-1}$ but 


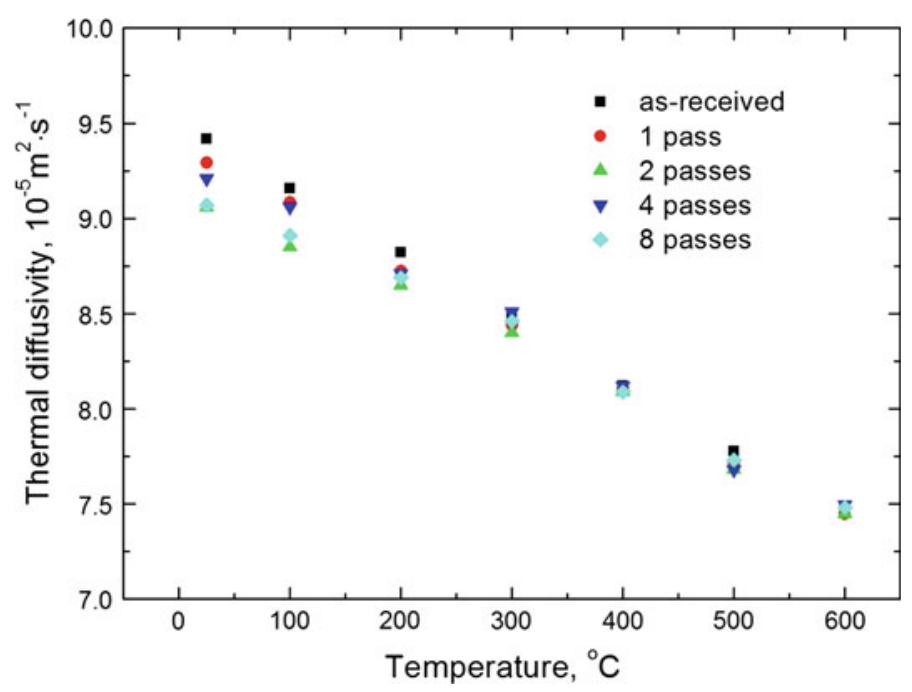

Fig. 6 Thermal diffusivity of ECAP aluminum 1060

decreased to $8.87 \times 10^{-5} \mathrm{~m}^{2} \cdot \mathrm{s}^{-1}$ after 8 passes. This difference remains constant up to $600^{\circ} \mathrm{C}$, but the difference in thermal diffusivity becomes minimal above $400^{\circ} \mathrm{C}$. At $600^{\circ} \mathrm{C}$, the thermal diffusivity of the specimen in the as-received state and after 8 passes are similar, being $7.48 \times 10^{-5} \mathrm{~m}^{2} \cdot \mathrm{s}^{-1}$ and $7.42 \times 10^{-5} \mathrm{~m}^{2} \cdot \mathrm{s}^{-1}$, respectively. The decrease of thermal diffusivity is regarded as being caused by the scattering of electrons from grain refinement. The thermal diffusivity is the lowest after 2 passes, presumably due to the formation of a grain band, and thermal conduction disturbance by dislocation, as seen from Fig. 2.

Figure 7 shows the coefficient of thermal expansion of the aluminum 1060 alloy at the as-received state and after 1, 2, 4, and 8 passes, using the dilatometer. It was confirmed that the coefficient of thermal expansion does not differ significantly between the as-received state and after different ECP passes. Figure 8 shows the density of aluminum 1060 alloy for the as-received state and after 1, 2, 4, and 8 passes, calculated using the measured thermal expansion coefficient. The documented value of aluminum is $2698 \mathrm{~kg} \cdot \mathrm{m}^{-3}$ [12], which is close to the estimated value for the as-received state, $2703 \mathrm{~kg} \cdot \mathrm{m}^{-3}$.

\subsection{Thermal Conductivity}

The thermal conductivity $(\lambda)$ was calculated with the experimentally measured specific heat capacity $\left(c_{p}\right)$, thermal diffusivity $(\alpha)$, and density $(\rho)$.

$$
\lambda=\rho c_{p} \alpha
$$

Figure 9 shows the thermal conductivity values of the aluminum 1060 alloy in the as-received state and after 1, 2, 4, and 8 passes. The thermal conductivity of Al 1060 


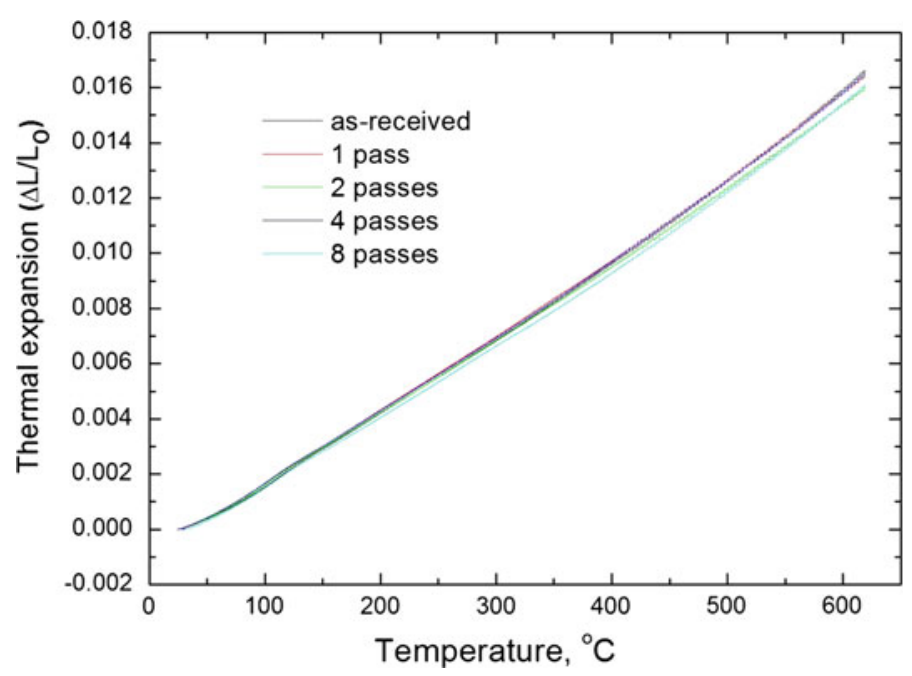

Fig. 7 Thermal expansion of ECAP aluminum 1060

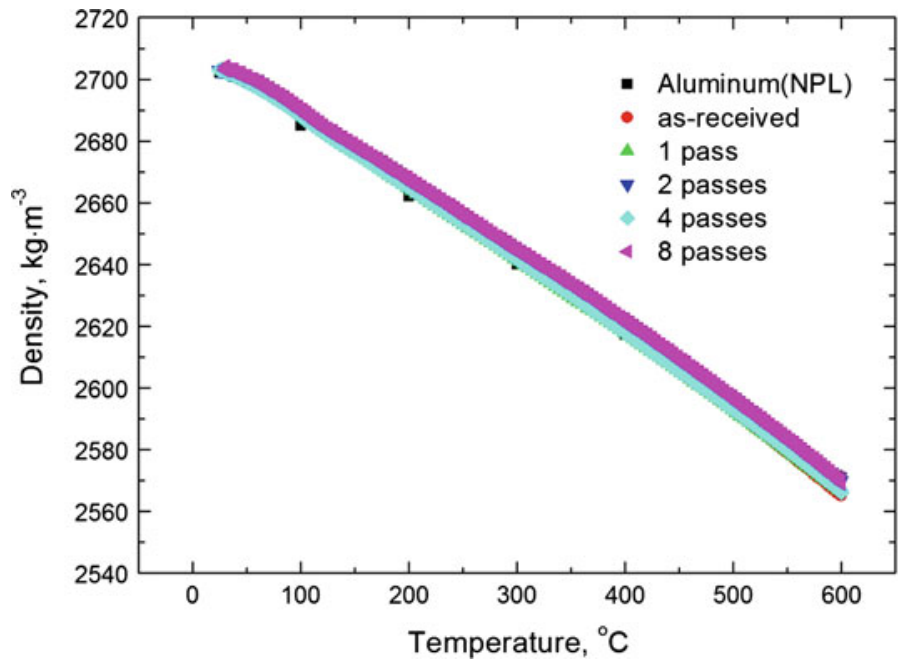

Fig. 8 Density of ECAP aluminum 1060

was $238 \mathrm{~W} \cdot \mathrm{m}^{-1} \cdot \mathrm{K}^{-1}$ in the as-received state and $223 \mathrm{~W} \cdot \mathrm{m}^{-1} \cdot \mathrm{K}^{-1}$ after 8 passes. Rather than uniformly decreasing with the increase in number of passes, the thermal conductivity is the highest after 1 pass, and then after 4 passes, 8 passes, and 2 passes, in descending order. This order of thermal conductivity was the same in Gedelman's experiment with ECAP-deformed pure copper at room temperature. This was explained using the equilibrium grain size distribution function [6], and Fig. 2 shows that our experiment suggests the same trend. In other words, the thermal conductivity is the lowest after 2 passes, due to the thermal conduction inhibition by the grain band formation and dislocation. The difference between the thermal 


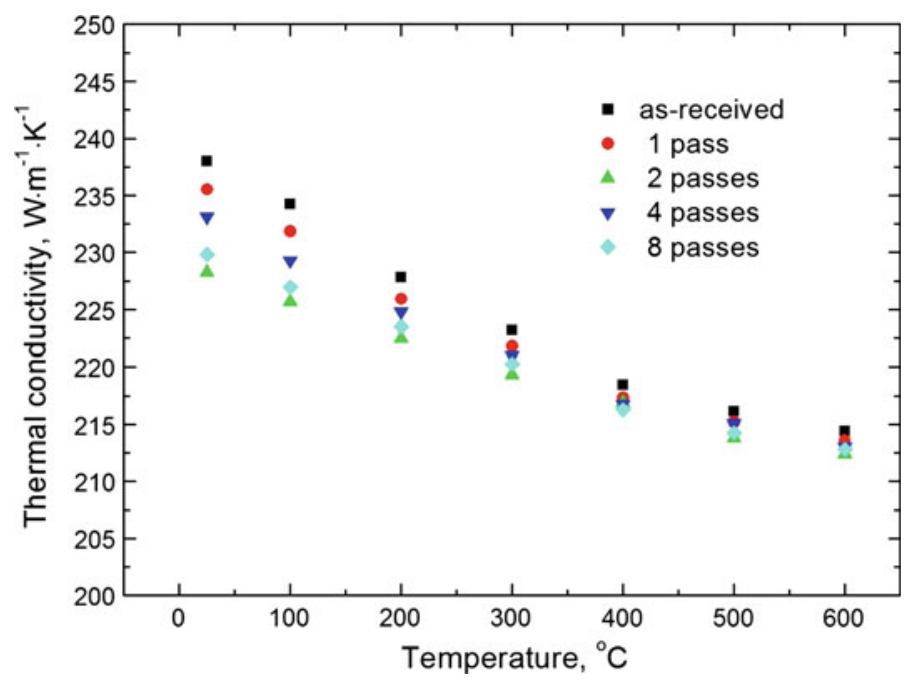

Fig. 9 Thermal conductivity of ECAP aluminum 1060

conductivity values decreases with the increase in temperature, because of the development and re-formation of grains. The recovery and reformation of materials at higher temperatures decreases the densities of dislocation, enables easier electron movements, and thereby reduces the difference of thermal conductivity in specimens, between the as-received and ECAP states.

Figure 10 shows the result of Vickers hardness measurements after $1 \mathrm{~h}$ annealing treatment of the specimen after 4 passes at each temperature. The Vickers hardness remains almost constant up to $150^{\circ} \mathrm{C}$, but shows a decreasing trend from $200^{\circ} \mathrm{C}$. This implies that the recovery began between $150{ }^{\circ} \mathrm{C}$ and $200^{\circ} \mathrm{C}$. The thermal-conductivity results in Fig. 9 also show that the difference between thermal conductivity values of the as-received and ECAP specimen were largely constant at room temperature and $100{ }^{\circ} \mathrm{C}$, but the difference decreased after $200^{\circ} \mathrm{C}$. Combined with the result of the Vickers hardness in Fig. 10, the recovery occurs at around $200^{\circ} \mathrm{C}$, as the reduction in the density of dislocation and the increase of the grain size by reformation decrease the difference between thermal conductivities, in the as-received and ECAP states.

Figure 11 shows the Wiedemann-Franz electrical conductivity, calculated with the measured thermal conductivity. The electrical resistivity at room temperature is $3.069 \times 10^{-8} \Omega \cdot \mathrm{m}$ for the as-received state and $3.179 \times 10^{-8} \Omega \cdot \mathrm{m}$ after 8 passes, about a $3 \%$ decrease, and is highest for 1 pass, 4 passes, 8 passes, and 2 passes in descending order. In line with the original purpose, the aluminum strength could be enhanced by ECAP without significant changes in the electrical conductivity, using aluminum refinement.

The four-probe electrical-resistivity measurements at room temperature are shown in Table 1. The four-probe electrical resistivity of the as-received state is $2.88 \times$ $10^{-8} \Omega \cdot \mathrm{m}$ and $2.95 \times 10^{-8} \Omega \cdot \mathrm{m}$ after 8 passes, with about $2.4 \%$ difference. This suggests that the grain refinement by ECAP significantly improves the strength, and the effects on electrical conductivity are minimal. There is an $\sim 6 \%$ difference between the 


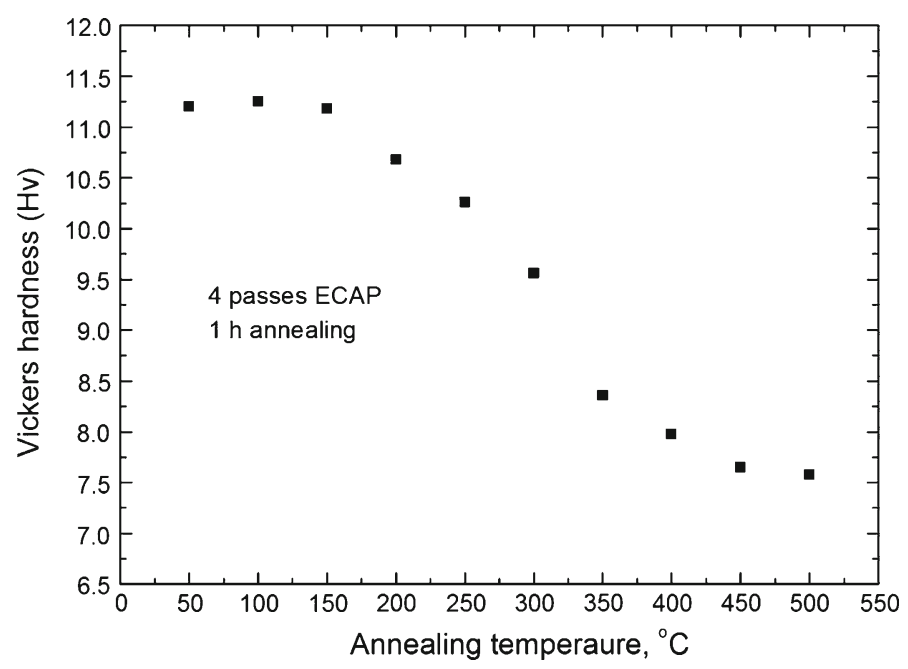

Fig. 10 Microhardness of ECAP aluminum 1060

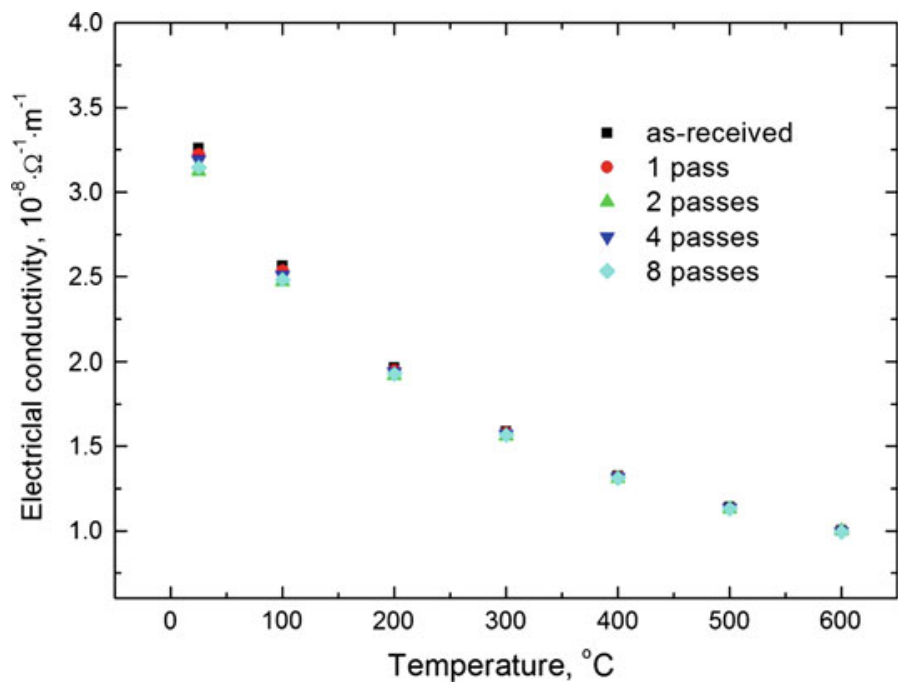

Fig. 11 Electrical conductivity of ECAP aluminum 1060

calculated electrical resistivity using the measured thermal conductivity (Fig. 11) and electrical resistivity, which is reasonable considering the errors of thermal property measurements and electrical measurements. Table 2 shows a comparison between the thermal property measurement and the reference value of aluminum. The measurements generally correspond to the reference values. 
Table 1 Electrical resistivity and electrical conductivity of ECAP Al 1060 alloy by four-point probe method

\begin{tabular}{lll}
\hline Sample & Electrical resistivity $(\Omega \cdot \mathrm{m})$ & Electrical conductivity $\left(\Omega^{-1} \cdot \mathrm{m}^{-1}\right)$ \\
\hline Al 1060 as-received & $2.88 \times 10^{-8}$ & $3.468 \times 10^{7}$ \\
ECAP 1 pass & $2.93 \times 10^{-8}$ & $3.415 \times 10^{7}$ \\
ECAP 2 passes & $2.95 \times 10^{-8}$ & $3.391 \times 10^{7}$ \\
ECAP 4 passes & $2.91 \times 10^{-8}$ & $3.435 \times 10^{7}$ \\
ECAP 8 passes & $2.95 \times 10^{-8}$ & $3.395 \times 10^{7}$ \\
\hline
\end{tabular}

Table 2 Thermal properties of aluminum 1060 and Emsley's data [12]

\begin{tabular}{lll}
\hline Properties & Al 1060 as-received & Emsley [12] Aluminum \\
\hline Thermal conductivity & $238 \mathrm{~W} \cdot \mathrm{m}^{-1} \cdot \mathrm{K}^{-1}$ & $237 \mathrm{~W} \cdot \mathrm{m}^{-1} \cdot \mathrm{K}^{-1}$ \\
Density & $2703 \mathrm{~kg} \cdot \mathrm{m}^{-3}$ & $2698 \mathrm{~kg} \cdot \mathrm{m}^{-3}$ \\
Thermal diffusivity & $9.418 \times 10^{-5} \mathrm{~m}^{2} \cdot \mathrm{s}^{-1}$ & $9.733 \times 10^{-5} \mathrm{~m}^{2} \cdot \mathrm{s}^{-1}$ \\
Specific heat capacity & $0.9398 \mathrm{~J} \cdot \mathrm{g}^{-1} \cdot \mathrm{K}^{-1}$ & $0.9025 \mathrm{~J} \cdot \mathrm{g}^{-1} \cdot \mathrm{K}^{-1}$ \\
Electrical resistivity & $2.88 \times 10^{-8} \Omega \cdot \mathrm{m}$ & $2.6548 \times 10^{-8} \Omega \cdot \mathrm{m}$ \\
Coefficient of thermal expansion & $23.38 \times 10^{-6} \mathrm{~K}^{-1}$ & $23.03 \times 10^{-6} \mathrm{~K}^{-1}$ \\
\hline
\end{tabular}

\section{Conclusions}

To study mechanical changes in the refined structure of aluminum 1060 by ECAP, the thermal conductivity was investigated based on the specific heat capacity, thermal diffusivity, and densities. The thermal conductivity decreased by $\sim 8 \%$ after 1 pass, compared to the as-received state. However, thermal-conductivity values after 2, 4, and 8 passes were not significantly different from that after 1 pass. The thermal conductivity does not decrease in an inversely proportional manner with the number of passes. This is the result of thermal-conductivity inhibition by grain band formation and dislocation density. The difference in thermal conductivities of the as-received state and an ECAP specimen becomes smaller above $200^{\circ} \mathrm{C}$, due to the recovery occurring between $150^{\circ} \mathrm{C}$ and $200^{\circ} \mathrm{C}$.

Open Access This article is distributed under the terms of the Creative Commons Attribution License which permits any use, distribution, and reproduction in any medium, provided the original author(s) and the source are credited.

\section{References}

1. R.Z. Valiev, R.K. Islamgaliev, I.V. Alexandrov, Prog. Mater. Sci. 45, 103 (2000)

2. D.H. Shin, K.T. Park, Mater. Sci. Eng. A410-A411, 299 (2005)

3. M. Cabibbo, E. Evangelista, C. Scalabroni, Micron 36, 401 (2005)

4. S. Komura, P.B. Berbon, M. Furukawa, Z. Horita, M. Nemoto, T.G. Landon, Scr. Mater. 38, 1851 (1998)

5. K.T. Park, D.Y. Hwang, Y.K. Lee, Y.K. Kim, D.H. Shin, Mater. Sci. Eng. A 341, 273 (2003) 
6. O.V. Gendelmana, M. Shapiro, Y. Estrin, R.J. Hellmig, S. Lekhtmakher, Mater. Sci. Eng. A 434, 88 (2006)

7. S. Lee, A. Utsunomiya, H. Akamatsu, K. Neishi, M. Furukawa, Z. Horita, T.G. Langdon, Acta Mater. 50, 553 (2002)

8. R. Kapoor, J.K. Chakravartty, Acta Mater. 55, 5408 (2007)

9. J.C. Lee, S.H. Lee, S.W. Kim, D.Y. Hwang, S.H. Shin, S.W. Lee, Thermochim. Acta 499, 100 (2010)

10. S.H. Lee, J.M. Park, C.K. Kim, Int. J. Thermophys. 28, 1578 (2007)

11. T. Azumi, Y. Takahashi, Rev. Sci. Instrum. 52, 1411 (1981)

12. J. Emsley, The Elements, 2nd edn. (Oxford University Press, London, 1990), pp. 14-15 